Annals of International Medical and Dental Research

E-ISSN: 2395-2822 | P-ISSN: 2395-2814

Vol-8, Issue-1 | January-February 2022

DOI: 10.53339/aimdr.2022.8.1.6

Page no- 38-42 | Section- Research Article (Otorhinolaryngology)

\title{
Effectiveness of Functional Endoscopic Sinus Surgery in Surgical Management of Ethmoid Polyps
}

\author{
Kumari Radha M. N1*, Anju Unnikrishnan², Manju.N3
}

\begin{abstract}
1Department of Otorhinolaryngology, Sreenarayana Institute of Medical Sciences, Chalakka, Ernakulam, Kerala, India.

Email: drradhagopinath@gmail.com Orcid ID: 0000-0002-5608-9580

${ }^{2}$ Assistant Professor, Department of E.N.T, Sreenarayana Institute of Medical Sciences, Chalakka, Ernakulam, Kerala, India.

Email: anju1687@gmail.com

Orcid ID: 0000-0002-8877-5841

3.Dr Manju. N., ESI Hospital, Olarikkara, Thrissur, Kerala, India .

Email: drmanjun@gmail.com

Orcid ID: 0000-0002-8152-6156

${ }^{*}$ Corresponding author
\end{abstract}

Received: 05 September 2021

Revised: 29 October 2021

Accepted: 10 November 2021

Published: 22 December 2021

\begin{abstract}
Background: Aim: To assess efficacy of functional endoscopic sinus surgery in surgical management of ethmoid polyps. Methods: One hundred twelve adult patients age ranged 18- 38 years of either gender with ethmoid polyps underwent FESS under general anesthesia. The extent of surgery was decided based on the findings in pre-operative CT scan of paranasal sinuses. Anterior ethmoidectomy, posterior ethmoidectomy, middle meatus antrostomy and clearance of frontal recess were performed in all the patients. Five functional criteria were evaluated as nasal obstruction , anosmia, rhinorrhea, post nasal drip, head ache and facial pain. Results: Pre- operative nasal obstruction percentage was 3.42 and post- operative ercentage was 2.10, Anosmia percentage was 2.14 and 1.15, Rhinorrhea percentage was 3.56 and 2.08 and ocular problem in 1 and synechia in 4 cases. Conclusions: Functional endoscopic sinus surgery found to be effective in management of ethmoid polyps and hence can be the treatment of choice.
\end{abstract}

Keywords:- Functional endoscopic sinus surgery, ethmoid polyps, nasal obstruction, rhinorrhea

\section{INTRODUCTION}

Functional endoscopic sinus surgery (FESS) is a minimally invasive technique that uses an endoscope to improve ventilation and drainage of sinus in addition to polyp removal.[1] The extent of surgery varies according to the extent of disease and surgeon's individual practice. This technique has been used for more than a decade in treating sino-nasal conditions. [2] Advantages are claimed over conventional surgery: permitting a better view of the surgical field, a more precise and thorough clearance of the inflammatory change with less mucosal damage, fewer complications and lower recurrence rates. $[3,4]$

Nasal polyp growths are round, soft, semitranslucent, pale or yellow glistening structures that originate from any part of the nasal mucosa or paranasal sinuses. Polyp development has been linked to chronic inflammation, allergy, autonomic nervous system dysfunction and genetic predisposition. [5] Polyposis is defined as a specific form of chronic rhinosinusitis characterized by bilateral and multifocal polyps 
Annals of International Medical and Dental Research

E-ISSN: 2395-2822 | P-ISSN: 2395-2814

Vol-8, Issue-1 | January-February 2022

DOI: 10.53339/aimdr.2022.8.1.6

Page no- 38-42 | Section- Research Article (Otorhinolaryngology)

. It can be isolated or associated with asthma (20\%-40\%) and aspirin intolerance, which define the Samter triad.6] Its incidence is increasing, reaching approximately $4 \%$ of the general population. Conventional polypectomy has lost its charm due to high rate of recurrence. [7] Nowadays FESS has emerged as a treatment of choice for nasal polyposis and chronic rhino sinusitis that is not responsive to aggressive medical treatment. [8] Considering this, we selected present study to assess effectiveness of endoscopic sinus surgery in surgical management of ethmoid polyps.

\section{MATERIAL AND METHODS}

A total of one hundred twelve adult patients age ranged 18- 38 years of either gender were selected for the study. Inclusion criteria $\mathrm{o}$ patients are above 18 years and up to 35 years .Exclusion criteria are patients less than 18 years of age ,malignancy involving nose and paranasal sinuses, patients with cystic fibrosis ciliary dyskinesia, revision FESS. Patients who had immunocompromised states due to diabetes mellitus, hypertension, chronic granulomatous diseases were also excluded. All selected patients were made aware of the study and their written consent was obtained. Ethical clearance from institutional review board was taken before study was commenced.

A thorough clinical examination was carried out - nasal endoscopy was done CT Scan head and paranasal sinuses done. FESS was done under general anesthesia. The extent of surgery was decided based on the findings in preoperative CT scan of paranasal sinuses. Anterior ethmoidectomy, posterior ethmoidectomy, middle meatus antrostomy and clearance of frontal recess were performed in all the patients. All patients were prescribed nasal steroid drops, oral antihistamines, saline nasal douche and antibiotics post operatively. Patients were assessed by nasoendoscopy post operatively and regular nasal toilet and debridement of nasal adhesions and crusting was done on each follow up visit. Patients were recalled regularly at 1st week, 2nd weeks, 1st month, 3rd month, 6th month and one year.

Six criteria were evaluated as nasal obstruction , anosmia, rhinorrhea, head ache and facial pain - Recurrent disease was defined as a condition of nasal polyposis that occurred in patients who had resolution of disease after surgery but appeared at a later date. After recording all the parameters, statistical analysis was carried out using Mann Whitney $U$ test. Level of significance was set below 0.05 .

\section{RESULTS}

Out of 112 patients, males were 62 and females were 50 [Table 1].

Pre- operative nasal obstruction percentage was 99 and post- operative was $20 \%$, Anosmia was $58 \%$ and $2 \%$, Mucopurulent Rhinorrhea was $88 \%$ and $12 \%$ and postnasal drip $75 \%$ and $5 \%$ head ache $62 \%$ and facial pain $20 \%$ preoperatively. Post- operatively both are nil . A significant difference was observed $(\mathrm{P}<0.05)$ [Table 2, Figure 1].

Common complications were synechia 56, infection 32, ocular problems and CSF leak 0. A significant difference was observed $(\mathrm{P}<0.05)$ [Table 3]. 
Annals of International Medical and Dental Research

E-ISSN: 2395-2822 | P-ISSN: 2395-2814

Vol-8, Issue-1 | January-February 2022

DOI: 10.53339/aimdr.2022.8.1.6

Page no- 38-42 | Section- Research Article (Otorhinolaryngology)

Table 1: Distribution of patients

\begin{tabular}{|l|l|l|}
\hline \multicolumn{2}{|c|}{ Total- 112 } \\
\hline Gender & Males & Females \\
\hline Number & 62 & 50 \\
\hline
\end{tabular}

Table 2: Assessment of parameters.

\begin{tabular}{|l|l|l|l|}
\hline Parameters & Pre- operative & Post- operative & P value \\
\hline Nasal obstruction & $99 \%$ & $20 \%$ & $<0.05$ \\
\hline Anosmia & $58 \%$ & $2 \%$ & $<0.05$ \\
\hline Rhinorrhea-mucopurlent & $88 \%$ & $12 \%$ & $<0.05$ \\
\hline Head ache & $62 \%$ & 0 & $<0.05$ \\
\hline Facial pain & $20 \%$ & 0 & \\
\hline
\end{tabular}

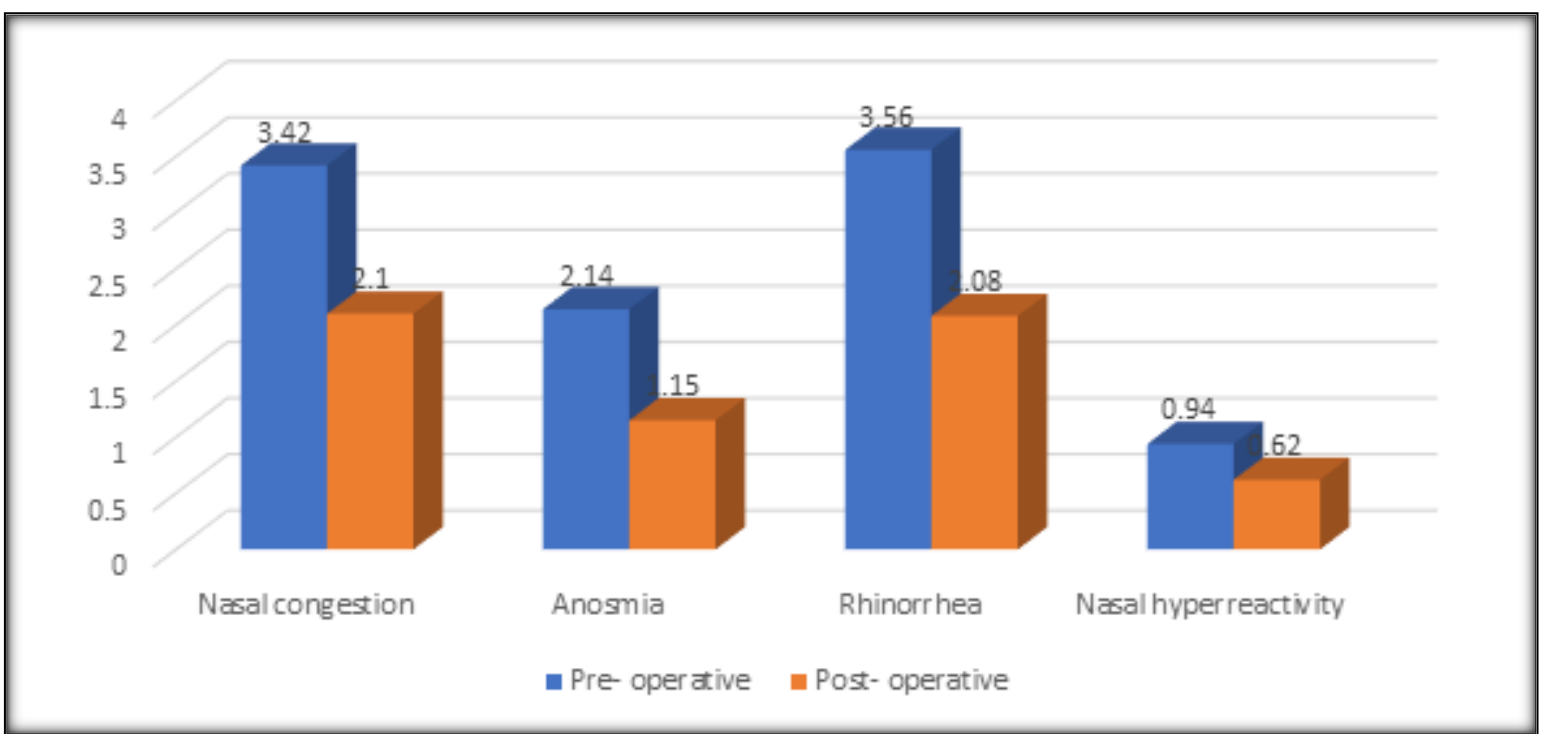

Figure 1:

Table 3: Complications of FESS

\begin{tabular}{|c|c|c|}
\hline Complications & Number & P value \\
\hline Synechia & 56 & \multirow[t]{3}{*}{$<0.05$} \\
\hline Infections & 32 & \\
\hline Recurrence & 24 & \\
\hline Ocular problems & & \\
\hline Chemosis & 11 & \\
\hline Echymosis & 21 & \\
\hline Lid oedema & 22 & \\
\hline Subconjunctival haemorrhage & 17 & \\
\hline Orbital fat prolapse & 10 & \\
\hline CSF leak & 0 & \\
\hline
\end{tabular}


Annals of International Medical and Dental Research

E-ISSN: 2395-2822 | P-ISSN: 2395-2814

Vol-8, Issue-1 | January-February 2022

DOI: 10.53339/aimdr.2022.8.1.6

Page no- 38-42 | Section- Research Article (Otorhinolaryngology)

\section{DISCUSSION}

Nasal polyps remain a significant challenge to the treating physician. The treatment modalities of nasal polyps encompass both medical and surgical modalities following the assessment of the patient. [9,10] Surgical treatment comprises of polypectomy which has a high recurrence rate, intranasal ethmoidectomy - a blind procedure and external ethmoidectomy with its inherent complication of external scar. All these shortcomings are overcome by FESS, which is fast becoming the surgical treatment of choice for nasal polyp disease. 11,12$]$ The first attempt at nasal and sinus endoscopy was performed by Hirschmann in 1901 using modified cystoscope. Since then, many advances have been made in the field of endoscopic sinus surgery.[13] In present study assessed functional endoscopic sinus surgery in management of ethmoid polyps.

Our results showed that out of 112 patients, males were 62 and females were 50. Gulati et al,[14] found that bilateral polypoidal mucosa in anterior ethmoidal cells was found in all 30 patients. Posterior ethmoidal air cells were involved in 23 subjects bilaterally and in 3 subjects unilaterally. Mucoid discharge in maxillary antrum was seen in 14 patients, pus in 4 patients, polyps and hypertrophic mucosa in 4 patients each. Sphenoid involvement in the form of polypoidal mucosa was seen in 4 patients bilaterally and in 2 patients unilaterally. Cheesy material along with polyps which on histopathological examination indicated aspergillosis was found in 2 patients. Anatomical variations in the form of accessory ostium (7 patients), bilateral concha bullosa (6 patients), bilateral paradoxical middle turbinate (5 patients) and polypoidal degeneration of both middle turbinates (5 cases) were noted. Relief in symptoms after surgery and endoscopic findings on follow up are summarized in [Table 2 and 3] respectively.

We observed that pre- operative nasal congestion score was 3.42 and post- operative score was 2.10, Anosmia score was 2.14 and 1.15, Rhinorrhea score was 3.56 and .08 and nasal hyperreactivity score was 0.94 and 0.62 pre- operatively and post- operatively respectively. Mayne et al,[15] found that the global functional score and GAS were significantly improved 3 years after these techniques were performed (global functional score changes from 8.65 to 3.11 for ethmoidectomy and from 8.15 to 4.2 for polypectomy; GAS, from 5.95 to 1.83 for ethmoidectomy and from 6.57 to 3.58 for polypectomy). Congestion, pain, and GAS were improved to a significantly greater extent in the ethmoidectomy group. The subsequent operation rate for symptomatic polyp recurrence was comparable $(9.1 \%$ vs $8.0 \%)$, with fewer local complications in the polypectomy group.

We found that common complications were CSF leak in 2, ocular problem in 1 and synechia in 4 cases. Gohar et al,[16] introduced mucosal sparing technique using endoscope for sinus surgery. He focused on removing key areas of obstruction to allow normal mucociliary function. Kenedy et al, [17] used the term FESS to describe the endoscopic technique of sinus surgery for treatment of nasal polyposis. Stamberger,[18] justified FESS by arguing that the nose and anterior ethmoids are responsible for almost all infections of frontal and maxillary sinuses. FESS is particularly used at osteomeatal area, clearing diseased air cells and mucosal 
Annals of International Medical and Dental Research

E-ISSN: 2395-2822 | P-ISSN: 2395-2814

Vol-8, Issue-1 | January-February 2022

DOI: 10.53339/aimdr.2022.8.1.6

Page no- 38-42 | Section- Research Article (Otorhinolaryngology)

contact areas. Ventilation and drainage of maxillary and frontal sinuses are re-established via their natural ostia.

\section{REFERENCES}

1. Dalziel K, Stein K, Round A, Garside R, Royle P. Systematic review of endoscopic sinus surgery for nasal polyps. Health Technol Assess. 2003;7(17): 1-159. doi: 10.3310/hta7170.

2. Damm M, Quante G, Jungehuelsing M, Stennert E. Impact of functional endoscopic sinus surgery on symptoms and quality of life in chronic rhinosinusitis. Laryngoscope. 2002;112(2):310-5. doi: 10.1097/00005537-200202000-00020.

3. Hwang H, Myung JE, Yi JW, Lee SS, Park J. Laparoscopic surgery versus open surgery for gastric cancer: big data analysis based on nationwide administrative claims data. Ann Surg Treat Res. 2020;99(3):138-145. doi: 10.4174/astr.2020.99.3.138.

4. Wigand ME. Transnasal ethmoidectomy under endoscopical control. Rhinology. 1981;19(1):7-15.

5. Kennedy DW, Zinreich SJ, Rosenbaum AE, Johns ME. Functional endoscopic sinus surgery. Theory and diagnostic evaluation. Arch Otolaryngol. 1985;111(9):57682. doi: 10.1001/archotol.1985.00800110054002.

6. Stammberger H. Endoscopic endonasal surgery--concepts in treatment of recurring rhinosinusitis. Part I. Anatomic and pathophysiologic considerations. Otolaryngol Head Neck Surg. 1986;94(2):143-7. doi: 10.1177/019459988609400202.

7. Stewart MG, Donovan DT, Parke RB Jr, Bautista MH. Does the severity of sinus computed tomography findings predict outcome in chronic sinusitis? Otolaryngol Head Neck Surg. 2000;123(1Pt1):81-4. doi: 10.1067/mhn.2000.105922.

8. Suzuki S, Yasunaga H, Matsui H, Fushimi K, Kondo K, Yamasoba T. Complication rates after functional endoscopic sinus surgery: analysis of 50,734 Japanese patients. Laryngoscope. 2015;125(8):1785-91. doi: 10.1002/lary.25334.

9. Lildholdt $\mathrm{T}$, Rundcrantz $\mathrm{H}$, Bende M, Larsen K. Glucocorticoid treatment for nasal polyps. The use of topical budesonide powder, intramuscular betamethasone, and surgical treatment. Arch Otolaryngol Head Neck Surg. 1997;123(6):595-600. doi: 10.1001/archotol.1997.01900060037006.

\section{CONCLUSIONS}

Functional endoscopic sinus surgery found to be effective in management of ethmoid polyps and hence can be the treatment of choice.

10. Senior BA, Kennedy DW, Tanabodee J, Kroger H, Hassab M, Lanza D. Long-term results of functional endoscopic sinus surgery. Laryngoscope. 1998;108(2):151-7. doi: 10.1097/00005537-199802000-00001.

11. Bolger WE, Brown CL, Church CA, Goldberg AN, Karanfilov B, Kuhn FA, et al. Safety and outcomes of balloon catheter sinusotomy: a multicenter 24-week analysis in 115 patients. Otolaryngol Head Neck Surg. 2007;137(1):10-20. doi: 10.1016/j.otohns.2007.02.006.

12. Bhattacharyya $\mathrm{N}$. Influence of polyps on outcomes after endoscopic sinus surgery. Laryngoscope. 2007;117(10):1834-8. doi: 10.1097/MLG.0b013e3180caa19d.

13. Nair S, Dutta A, Rajagopalan R, Nambiar S. Endoscopic sinus surgery in chronic rhinosinusitis and nasal polyposis: a comparative study. Indian J Otolaryngol Head Neck Surg. 2011;63(1):50-55. doi:10.1007/s12070011-0119-8

14. Gulati P, Raman W, Antariksh D. Efficacy of Functional Endoscopic Sinus Surgery in the treatment of Ethmoidal polyps. Internet J Otorhinol. 2007;7(1):150-7.

15. Devars du Mayne $M$, Prulière-Escabasse $V$, Zerah-Lancner F, Coste A, Papon JF. Polypectomy compared with ethmoidectomy in the treatment of nasal polyposis. Arch Otolaryngol Head Neck Surg. 2011;137(2):111-7. doi: 10.1001/archoto.2010.255.

16. Gohar MS, Niazi SA, Niazi SB. Functional Endoscopic Sinus Surgery as a primary modality of treatment for primary and recurrent nasal polyposis. Pak J Med Sci. 2017;33(2):380-382. doi:10.12669/pjms.332.11800

17. Kennedy DW, Zinreich SJ, Rosenbaum AE, Johns ME. Functional endoscopic sinus surgery. Theory and diagnostic evaluation. Arch Otolaryngol. 1985;111(9):57682. doi: 10.1001/archotol.1985.00800110054002.

18. Stammberger H. Endoscopic endonasal surgery--concepts in treatment of recurring rhinosinusitis. Part I. Anatomic and pathophysiologic considerations. Otolaryngol Head Neck Surg. 1986;94(2):143-7. doi: $10.1177 / 019459988609400202$.

Source of Support: Nil, Conflict of Interest: None declared 